\title{
Anisotropy of Magnetic Susceptibility (AMS) of Bostonite Rocks, Um-Gir and El-Atshan-II Uranium Prospect Areas, Central Eastern Desert, Egypt
}

\author{
Hussein F. Abd El-Salam \\ Nuclear Materials Authority, El Maadi, Cairo, Egypt \\ Email: elfaroukhessein@yahoo.com
}

How to cite this paper: El-Salam, H.F.A. (2022) Anisotropy of Magnetic Susceptibility (AMS) of Bostonite Rocks, Um-Gir and El-Atshan-II Uranium Prospect Areas, Central Eastern Desert, Egypt. Geomaterials, 12, $1-14$.

https://doi.org/10.4236/gm.2022.121001

Received: November 29, 2021

Accepted: January 25, 2022

Published: January 28, 2022

Copyright (อ 2022 by author(s) and Scientific Research Publishing Inc. This work is licensed under the Creative Commons Attribution International License (CC BY 4.0).

http://creativecommons.org/licenses/by/4.0/

\section{(c) (i) Open Access}

\begin{abstract}
Um-Gir and El-Atshan-II areas represent important structurally-controlled radioactive anomalies and have become promising areas for $\mathrm{U}$ exploration. The bostonite rocks represent the most promising rock unit in the two studied areas. They form the most promising rocks due to their high radioactivity and, hence uranium mineralization. Anisotropy of magnetic susceptibility (AMS) measurements was carried out for Um-Gir and El-Atshan-II bostonite rocks. The AMS results show that the mean magnitude of magnetic susceptibilities is low, of the order of $10^{-5}$ S.I. units. Consequently, the bostonite rocks of the two areas are considered as non-magnetic, reflecting the presence of hematite as the main ferromagnetic mineral. These results are in agreement with the measurements of initial remnant magnetization (NRM) and the results of isothermal remnant magnetization (IRM) for the two areas. Besides, the results of magnetic anisotropy degree $\left(P_{J}\right)$, refer to and concluded that the magnetic fabric of bostonite of two the areas has secondary fabric. AMS results clearly show the differences between the bostonite dyke of Um-Gir and Bostonite sill of El Atshan-II. The lineation $\left(P_{1}\right)>$ foliation $\left(P_{3}\right)$, and the negative values of the ellipsoid shape $(T)$ of Um-Gir bostonite reflect clearly magnetic lineation (prolate ellipsoid). However, in El Atshan-II, $\left(P_{3}>P_{1}\right)$, the values of $T$ are positive, which indicate the predominance of magnetic foliation (oblate ellipsoid) over lineation. Furthermore, the foliation planes of the bostonite dyke of Um-Gir possess a shallow to moderate inclination and a nearly N-S direction, while, the foliation planes of the bostonite sill of El-Atshan-II show a shallow to moderate inclination and a NNE direction. Finally, the AMS method is a powerful tool for detecting the structures that affect the bostonite rocks of the two studied areas.
\end{abstract}




\section{Keywords}

Central Eastern Desert Egypt, Bostonite Rocks, AMS, NRM, IRM

\section{Introduction}

The anisotropy of magnetic susceptibility (AMS) of rocks, which investigates the preferred orientation of magnetic minerals, contains information about both the grain susceptibilities and their orientation-distribution. A preferential orientation-distribution of mineral grains develops during various geological processes, such as water flow in sediments, magma flow in igneous rocks or ductile deformation in metamorphic rocks [1]. Among the mechanisms of the mass transport within the Earth's crust and the upper mantle the magma movement within the dykes is very important. In some dykes, the magma movement is represented by almost free flow infilling more or less open fractures in the host rocks, while it has character of forceful injection of the host rocks in the other dykes. The magnetic fabric originated by the free flow is characterized by the magnetic foliation and magnetic lineation approximately parallel to the dyke plane (normal fabric) whereas the forceful injection gives rise to the magnetic foliation perpendicular to the dyke plane defining the intermediate or inverse magnetic fabric [2].

Um-Gir and El Atshan-II uranium prospect areas are located in the Central Eastern Desert, about $40 \mathrm{~km}$ southwest of Qusseir city on the Red Sea western Coast. They lie at the intersections of about $25^{\circ} 51^{\prime} \mathrm{N}$ lat. and $34^{\circ} 06^{\prime} \mathrm{E}$ Long., and $25^{\circ} 51^{\prime} \mathrm{N}$ lat. and $34^{\circ} 06^{\prime} \mathrm{E}$ Long for Um-Gir and El Atshan-II, respectively (Figures 1(a)-(c)). The two study areas represent one of the important structurally-controlled radioactivity prospects in the Central Eastern Desert of Egypt. Bostonite is the most radioactive rock unit in the two study areas. Three features confirm the structural control behavior of radioactivity and, hence uranium mineralization in two the study areas. The first feature is the occurrence of all significant anomalies as well as uranium mineralization at the contact zones. The second one is the general higher radioactivity at both contacts conforming to fault planes. The last and third feature is the diminishing of radioactivity from maximum around fractures or fault planes [3].

Anisotropy of magnetic susceptibility (AMS) of fine-grained magnetic particles has been commonly used in a variety of environmental and tectonic studies [4]. This study is performed using the anisotropy of magnetic susceptibility (AMS) measurements which is a powerful tool of structural analysis, allows insight on microstructures and identifies the prevailing structures that affected the bostonite rocks during or after their original emplacements. Therefore, this method will be applied to the bostonites in the two areas to: 1) Describe the behavior of magnetic susceptibilities in the bostonites, which represent the main radioactive rock unit in the studied areas, since the values of magnetic susceptibilities give the first indication of rock-forming magnetic minerals, 2) Determine 


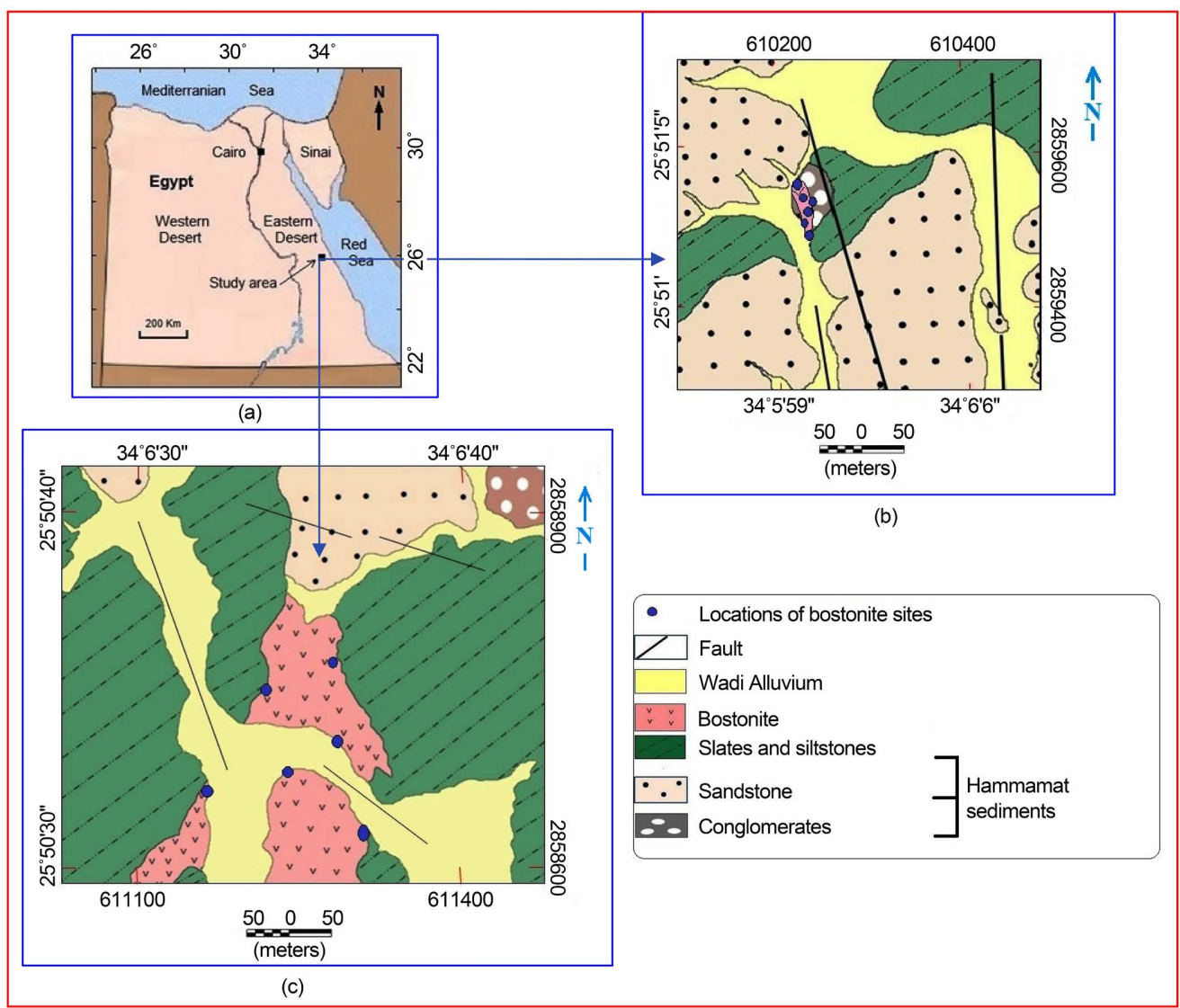

Figure 1. (a) Location map of the two study areas, (b) Geological map of Um-Gir uranium prospect area, (c) Geological map of El Atshan-II uranium prospect area, Central Eastern Desert, Egypt [6].

the directions of magma flow, 3) Investigate the preferred orientations of the prevailing structures affecting bostonites during or after their original emplacement.

\section{Geological Setting}

Many authors studied the geologic setting and described the rock alterations and mineralizations of Um-Gir and El Atshan-II areas, and their surroundings [3] [5] [6]. Generally, Um-Gir and El Atshan-II areas are mainly covered by basement rocks of Late Precambrian age, represented by different varieties of the Hammamat sediments, intruded by bostonite (Figure 1(b) \& Figure 1(c)).

1) Hammamat sediments

The Hammamat sediments (the oldest rock unit in the two study areas) are composed of clastic sediments, generally characterized by their molasse type, purple-red to brick -red and green to geryish colours. They form a thick succession of interbedded conglomerates, sandstones, siltstones and slates.

\section{2) Bostonite}

The bostonites of Um-Gir form thin dykes and appear on the surface of about 5 - $10 \mathrm{~m}$ thick. The bostonite rocks are fine-grained, buff in colour and massive, but the weathered parts are pale cream yellow, with pitted surface. The fractured rock 
is usually altered where most of the joints and fractures are stained or filled with various alteration products, commonly including iron and manganese oxides, with carbonates and clayey materials, and so the rock becomes brown in colour [7].

The bostonite rock-bearing uranium mineralization at El Atshan-II locality forms a sill intruding the sandstones and conglomeratic sandstone beds of the Post Geosynclinal sediments. This is of a cream colour with deep colours along the contacts, fractures and zones due to hematitization. This grain size of the bostonite is fine to medium and of a subtrachytic texture [5].

3) Alteration features

Alteration features are well developed at the radioactive occurrences of UmGir and El Atshan-II areas. Both of the bostonite rocks and the country rocks of the Hammamat sediments are altered by hydrothermal solutions. The most predominant alteration features are represented by hematitization and kaolinitazation [7].

\section{4) Structural controls}

Structural controls were carried out [8] on a regional area that covers about 33 $\mathrm{km}^{2}$ includes El Atshan, El Atshan-II, Wadi Um Gir and Wadi El Rahia. These studies included the structural controls of radioactive mineralizations in the surface and on the subsurface as well as their relation to each other. [8] Found that the foliation and bedding in the studied area are exhibited by the Hammamat sediments and the Geosynclinals Metamorphosed Sediments. It was found that the NE-SW trend of foliation is the most abundant and exhibited by metamudstones, sandstones and siltstones. Meanwhile, the NNW-SSE trend is less abundant and shows in the greyish green sandstones. The joints in the Geosynclinal and Hammamat sediments are found in various sets; the most important of which are the NE-SW and NW-SE sets, followed by the ENE-WSW, WNWESE and NNW-SSE sets, while the least abundant one is that striking N-S. The faults cutting the Metamorphosed Geosynclinal and the Hammamat sediments possess variable trends, where the NW-SE and NE-SW trends are abundant, and the NNW-SSE and ENE-WSW are less abundant, the NNE-SSW, N-S and E-W are scarce. Besides, it was found that the bostonites occurring as sills, dykes and necks are the main rocks connected with uranium mineralization in the studied areas.

(Figure 2) shows a field photo, illustrating bostonite sill of El Atshan-II and its contacts with slate and Wadi sediments.

\section{Anisotropy of Magnetic Susceptibility (AMS) Studies}

The sources of magnetic susceptibilities of rocks and their anisotropies provide the most fundamental data for the interpretation of geophysical magnetic surveying [9]. Rock magnetic studies are always useful in the analysis of rock fabrics, the determination of preferred grain orientations in rocks, the definition of current directions, the specifications of magmatic flow paths and strain histories by relating magnetic anisotropy to mineral-grain-shape alignments and crystallographic preferred orientations [4] [10] [11] [12]. 


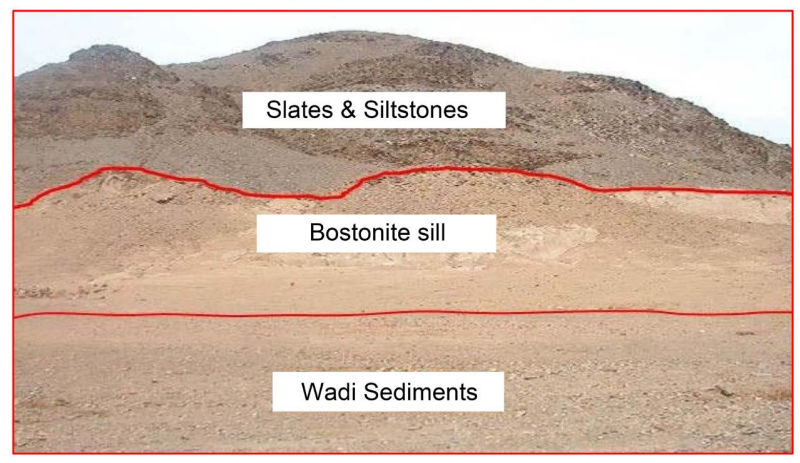

Figure 2. Photograph showing bostonite the sill of Atshan-II uranium prospect area, Central Eastern Desert, Egypt.

The output of AMS measurements is an ellipsoid of magnetic susceptibility (AMS ellipsoid) defined as the length and orientation of its three principal axes, $K_{1} \geq K_{2} \geq K_{3}$ the three eigenvectors of the susceptibility tensor [4]. $K_{1}$ defines the maximum magnetic susceptibility ( $\left.K_{\max }\right)$ or the direction, where most of the magnetic grains are aligned. $K_{2}$ is defined as the intermediate $\left(K_{\text {int }}\right)$ and $K_{3}$ as the minimum magnetic susceptibility $\left(K_{\min }\right)$.

When measured, each AMS eigenvector is determined with two uncertainty angles, which define the regions, where each principal susceptibility direction lies with a probability of $95 \%$. AMS ellipsoid shapes are classified according to the relationships between the magnetic susceptibility eigenvalues, as seen on (Figure 3).

\subsection{Sampling and Measurements}

The bostonites of Um-Gir and El Atshan-II areas were sampled at 12 sites. These samples were collected from the U-mineralized zones. Oriented block samples, only, were collected from all sites, whereas drilled core samples were not accessible. These samples were oriented in situ, while still attached to the outcrops, using a solar compass [13]. The block samples were subsequently reoriented in the laboratory, where cylindrical samples of $2.5 \mathrm{~cm}$ diameter were drilled. Generally, three to five core samples were drilled from each block sample. Each core sample was then sliced into one to three standard core specimens of $2.2 \mathrm{~cm}$ length. This sampling scheme produced a total of 75 core samples. The coordinates of sampling sites (Figure 1(b) \& Figure 1(c)), were accurately determined in the field, using a GPS instrument. Hammamat sediments are composed of very thin sheets, so there is no specific way to collect samples from these thin sheets and preparing them for drilling and measurements.

The equipment used in this study is the Minisip susceptibility meter. It is a computer-controlled instrument which provides a mean of measuring both the bulk susceptibility and the AMS of a rock sample, with a sensitivity of $10^{-7}$ Gauss/Oersted. Bulk susceptibility measurement occurs within 4 seconds. It depends on a balanced air-core transformer, having a mechanism that allows a rock sample to be introduced into a section of a core, thus, unbalancing it. The 


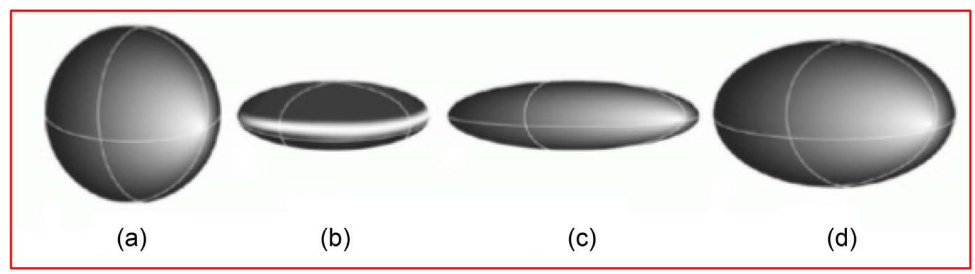

Figure 3. Shape of AMS ellipsoids: (a) $\mathrm{kmax} \approx \mathrm{kint} \approx \mathrm{kmin}$; isotropic susceptibility, the AMS ellipsoid is a sphere; (b) $\mathrm{kmax} \approx \mathrm{kint}>\mathrm{kmin}$; the AMS ellipsoid is an oblate shape; (c) $\mathrm{kmax} \approx \mathrm{kint}<\mathrm{kmin}$; the AMS ellipsoid has a prolate shape; (d) $\mathrm{kmax}>\mathrm{kint}>\mathrm{kmin}$; the AMS ellipsoid is triaxial [1].

degree of unbalance is a measure of the bulk susceptibility along the cylindrical axis [14].

For the present study, five parameters were calculated; mean susceptibility [15], Anisotropy degree [16], Magnetic lineation [17], Magnetic foliation [18] and Ellipsoid shape [16].

\subsection{Results and Analysis}

\subsubsection{Um-Gir Bostonite Dyke}

Measurements of magnetic susceptibility and AMS were carried out for a total of 37 core samples, collected from 6 sites. Table 1 illustrates the site mean magnetic susceptibility as well as the mean magnitude and orientation of the AMS parameters for each site.

Magnetic susceptibility displayed very low values with a site-mean ranging between $8.368 \times 10^{-5}$ and $14.447 \times 10^{-5}$ S.I. units and an arithmetic mean of $11.6045 \times 10^{-5}$ S.I. units.

The anisotropy degree, $P_{\text {}}$, showed high values (Table 1 ), with a site-mean ranging between 1.211 and 1.332, and an arithmetic mean 1.261. The relation between the anisotropy degree and magnetic susceptibility (Figure 4(a)) reveals that all samples of bostonite rock are located in a very close range with high degree of deformation.

The magnetic lineation, $P_{1}$ values are low and homogenous, with a site-mean ranging between 1.012 and 1.020 and an arithmetic mean of 1.015. The magnetic foliation, $P_{3}$ is smaller than $P_{1}$ with a site-mean ranging between 1.007 and 1.013 and an average 1.009 , reflecting the predominance of magnetic lineation (prolate ellipsoid) over foliation (Table 1). The ellipsoid shape change in the sampling area is further presented by the $P_{3}$ versus $P_{1}$ plot (Figure 4(b)), which resembles the Flinn deformational plot used by structural geologists [19]. The line of unit slope which, passes through the origin, separates the oblate ellipsoids from prolate ellipsoids $\left(P_{1}>P_{3}\right)$. Another diagram for describing the ellipsoid shape of the AMS parameters is shown on (Figure 4(c)), in which the region above the horizontal axis represents an oblate ellipsoid and the region below represents a prolate ellipsoid. The $P_{3}$ versus $P_{1}$ plot refers that all sites fall within the lineating field (Figure 4(b)). This is also evident from the negative values of $T$ parameter that ranges from -0.169 to -0.35 (Table 1 ). On the other hand, the anisotropy degree $P_{J}$ shows some increase with increasing prolateness (Figure $4(\mathrm{c})$ ). 
Table 1. Site-mean magnetic susceptibility and AMS parameters for the bostonite rock of Um Gir uranium prospect area, Central Eastern Desert, Egypt.

\begin{tabular}{|c|c|c|c|c|c|c|c|c|c|c|c|c|}
\hline \multirow{2}{*}{ Site } & \multirow{2}{*}{$N$} & \multirow{2}{*}{$K \times 10^{-5}$} & \multirow{2}{*}{$P_{j}$} & \multirow{2}{*}{$T$} & \multirow{2}{*}{$P_{1}$} & \multirow{2}{*}{$P_{3}$} & \multicolumn{6}{|c|}{ Magnetic susceptibility axes } \\
\hline & & & & & & & $D_{\max }$ & $I_{\max }$ & $D_{\text {int }}$ & $I_{\text {int }}$ & $D_{\min }$ & $I_{\min }$ \\
\hline$\underline{\mathrm{U}} \mathrm{G} .1$ & 6 & 13.251 & 1.221 & -0.237 & 1.012 & 1.008 & 166 & 48 & 352 & 11 & 285 & 13 \\
\hline U G. 2 & 5 & 11.064 & 1.316 & -0.169 & 1.016 & 1.010 & 172 & 42 & 359 & 9 & 270 & 15 \\
\hline$\underline{\mathrm{U}} \mathrm{G} .3$ & 7 & 12.450 & 1.248 & -0.350 & 1.012 & 1.006 & 172 & 38 & 352 & 10 & 281 & 13 \\
\hline$\underline{\mathrm{U}} \mathrm{G} .4$ & 6 & 14.447 & 1.332 & -0.300 & 1.014 & 1.007 & 166 & 44 & 365 & 10 & 271 & 11 \\
\hline$\underline{\mathrm{U}} \mathrm{G} .5$ & 8 & 10.047 & 1.242 & -0.218 & 1.016 & 1.010 & 174 & 39 & 359 & 7 & 270 & 9 \\
\hline$\underline{\text { U G.6 }}$ & 5 & 8.368 & 1.211 & -0.209 & 1.020 & 1.013 & 174 & 37 & 359 & 8 & 270 & 7 \\
\hline Mean & $\ldots$ & 11.604 & 1.261 & -0.247 & 1.015 & 1.009 & 171 & 41 & 357 & 9 & 274 & 11 \\
\hline
\end{tabular}

$N$ : Number of measured core samples in each site. $K$ : Volume magnetic susceptibility, in S.I. units. $P_{J} \& T:$ Magnitude of anisotropy and ellipsoid shape respectively [16]. $P_{1} \& P_{3}$ : Lineation [17] and foliation [18] respectively. $D_{\max .} \& I_{\max }$ : Declination and inclination of the maximum susceptibility axes, in degrees. $D_{\text {int. }} \& I_{\text {int }}$. Declination and inclination of the intermediate susceptibility axes, in degrees. $D_{\min }$ \& $I_{\min }$. Declination and inclination of the minimum susceptibility axes, in degrees.

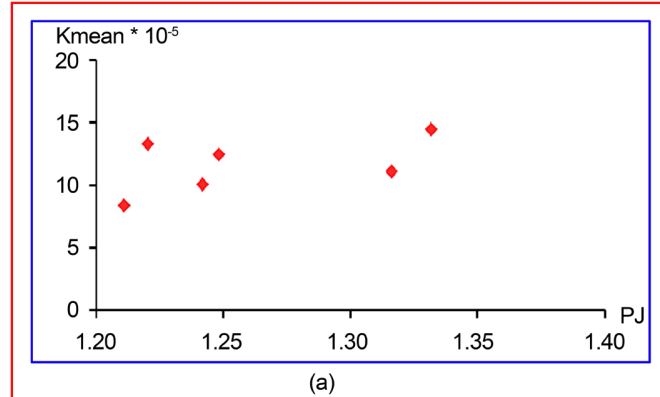

(a)

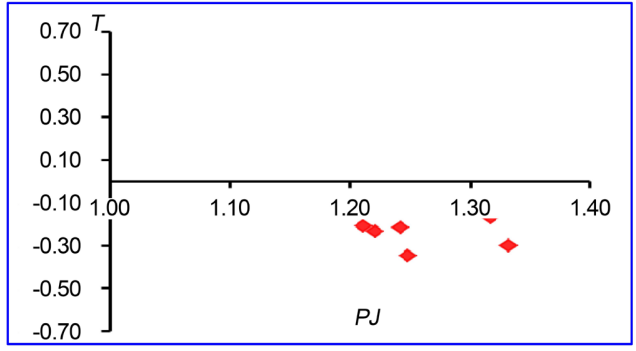

(c)

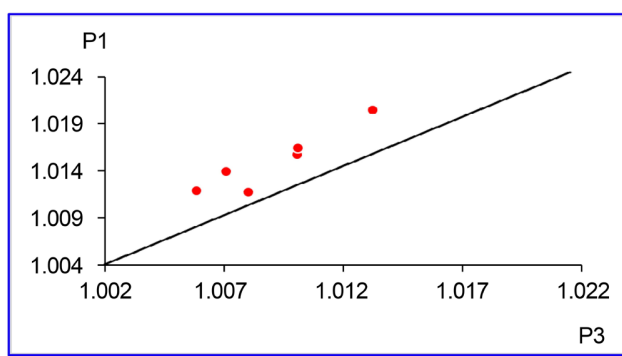

(b)

Figure 4. Relationships between: (a) Anisotropy degree $\left(P_{J}\right)$ and magnetic susceptibility $(K)$, (b) Foliation $\left(P_{3}\right)$ versus lineation $\left(P_{1}\right)$ and $(\mathrm{c})$ anisotropy degree $\left(P_{J}\right)$ and ellipsoid shape $(T)$ of the Bostonite rocks, Um-Gir uranium prospect area, Central Eastern Desert, Egypt.

The distribution of principal magnetic susceptibility axes for both the individual sites and all sites, are represented on the stereographic projections (Figure 5). For the six sites, they exhibit relatively well-grouped $K_{1}$ axes, with shallow inclinations. $K_{1}$ and $K_{3}$ which, show a good cluster within shallow foliation planes that strike in a nearly N-S direction. $K_{1}$ axes (magnetic lineation) are scattered along a single NNE direction, with moderate inclinations (average of $41^{\circ}$ ). $K_{2}$ axes show the same behavior as $K_{1}$, with the same trend and shallow inclinations. The $K_{3}$ axes (magnetic foliation poles) are shallow (average of $11^{\circ}$ ) and trend in a general NE-SW direction. 


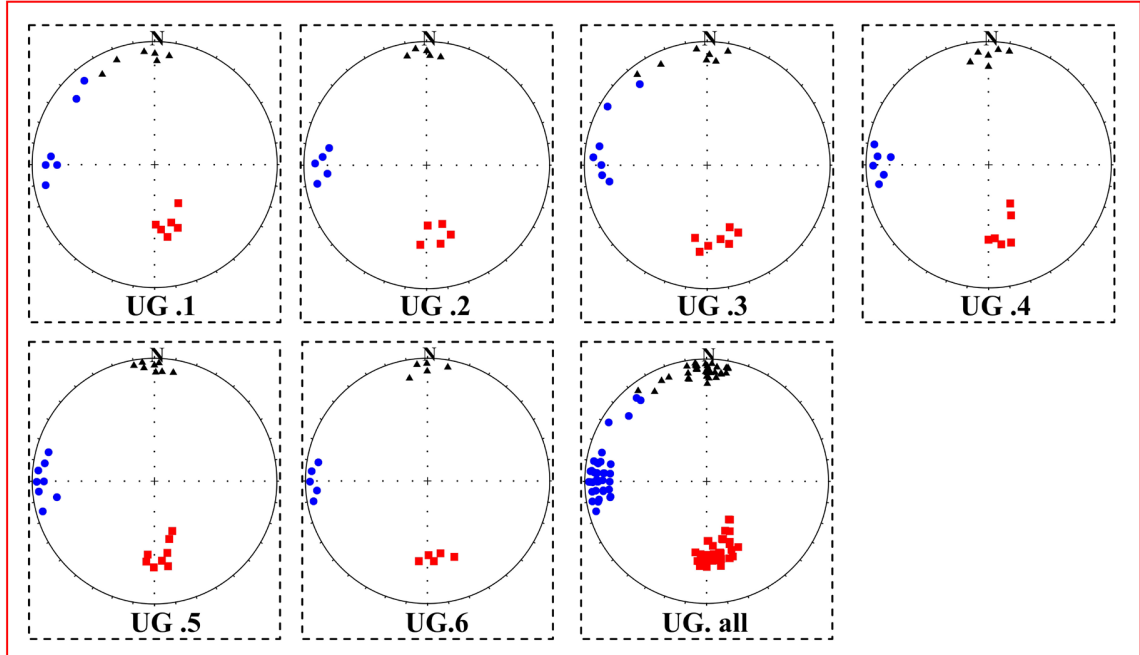

Figure 5. Equal-area lower hemisphere stereographic projections of the principal magnetic susceptibility axes for the 6 sites from the Bostonite Um-Gir uranium prospect area, Central Eastern Desert, Egypt. - Maximum axes $\left(K_{1}\right)$. $\Delta$ Intermediate axes $\left(K_{2}\right)$. Minimum axes $\left(K_{3}\right)$.

\subsubsection{El Atshan-II Bostonite Sill}

Measurements of magnetic susceptibility and AMS were carried out for a total of 38 core samples collected from 6 sites. Table 2 illustrates the site mean magnetic susceptibility as well as the mean magnitude and orientation of the AMS parameters for each site.

Magnetic susceptibility displayed very low values, with a site-mean ranging between $10.710 \times 10^{-5}$ and $27.191 \times 10^{-5}$ S.I. units and arithmetic mean of 16.692 $\times 10^{-5}$ S.I. units.

The anisotropy degree, $P_{\text {, }}$, has high values (Table 2), with a site-mean ranging between 1.224 and 1.368, and arithmetic mean of 1.289. There is no relation between the anisotropy degree and magnetic susceptibility (Figure 6(a)).

The magnetic lineation, $P_{1}$, values are low and homogeneous with arithmetic mean of 1.012, while the magnetic foliation, $P_{3}$, is higher than $P_{1}$, with arithmetic mean of 1.017. This reflects clear predominance of magnetic foliation (oblate ellipsoid) over lineation (Figure 6(b)). This is also reflected in the positive values of $T$ parameter (Table 2). The relation between the susceptibility ellipsoid $T$, and the anisotropy degree, $P_{5}$, of all samples of bostonites of El Atshan-II area are located also, in a very close range, with a high degree of deformation (Figure $6(c))$.

Distribution of the principal magnetic susceptibility axes for both the individual sites and all sites are represented on the stereographic projections (Figure 7). For the six sites, they exhibited relatively well-grouped $K_{3}$ axes, with shallow inclinations. $K_{1}$ and $K_{2}$ which show a good cluster within moderate foliation planes that strike in a NNE-SSW direction. $K_{1}$ axes (magnetic foliation) are scattered along a single NNE direction, with moderate inclinations (average of $46^{\circ}$ ). The $K_{3}$ axes (magnetic foliation poles) are shallow (average of $23^{\circ}$ ) and trend in a general WNW-ESE direction. 


\section{Discussion}

AMS results show that the mean magnitude of magnetic susceptibility is low, of the order of $10^{-5}$ S.I. units (Table $1 \&$ Table 2). The low mean of magnetic susceptibility value is a result of the rock being composed mainly of paramagnetic and diamagnetic minerals [20]. According [21] the bostonite rocks are considered as non-magnetic rocks, reflecting the presence of hematite as the main ferromagnetic mineral. This is in agreement with the results of the initial natural remanent magnetization (NRM) measurements which indicate relatively low values with arithmetic mean of Um-Gir area uranium prospect $\left(1.77 \times 10^{-2} \mathrm{~A} / \mathrm{m}\right)$ and of Atshan-II uranium prospect area $\left(1.98 \times 10^{-2} \mathrm{~A} / \mathrm{m}\right)$ Table 3 . Besides, isothermal remanent magnetization (IRM) experiments confirmed that hematite was regarded as the main carrier for this magnetization (Figure 8 \& Figure 9). As the bostonite samples were collected from the mineralized zones, hence, they were subjected to a subsequent hematization and kaolinization alterations as a result of hydrothermal solutions [7] which led to the replacement of magnetite by hematite. Petrographic investigation carried out by [3], indicates that epodite, zircon sphene and hematite are the main accessory minerals in bostonites.

Table 2. Site-mean magnetic susceptibility and AMS parameters for the bostonite rock of El Atshan-II uranium prospect area, Central Eastern Desert, Egypt.

\begin{tabular}{|c|c|c|c|c|c|c|c|c|c|c|c|c|}
\hline \multirow{2}{*}{ Site } & \multirow{2}{*}{$N$} & \multirow{2}{*}{$K \times 10^{-5}$} & \multirow{2}{*}{$P_{j}$} & \multirow{2}{*}{$T$} & \multirow{2}{*}{$P_{1}$} & \multirow{2}{*}{$P_{3}$} & \multicolumn{6}{|c|}{ Magnetic susceptibility axes } \\
\hline & & & & & & & $D_{\max }$ & $I_{\max }$ & $D_{\text {int }}$ & $I_{\text {int }}$ & $D_{\min }$ & $I_{\min }$ \\
\hline$\underline{\text { At. } 1}$ & 5 & 27.191 & 1.241 & 0.385 & 1.012 & 1.027 & 260 & 50 & 33 & 14 & 130 & 25 \\
\hline$\underline{\text { At. } 2}$ & 7 & 22.486 & 1.317 & 0.199 & 1.011 & 1.015 & 276 & 47 & 32 & 18 & 134 & 26 \\
\hline At. 3 & 7 & 13.522 & 1.368 & 0.140 & 1.008 & 1.009 & 253 & 44 & 39 & 18 & 130 & 21 \\
\hline At. 4 & 6 & 12.491 & 1.224 & 0.394 & 1.007 & 1.016 & 290 & 49 & 35 & 30 & 127 & 14 \\
\hline At. 5 & 7 & 10.710 & 1.238 & 0.075 & 1.018 & 1.019 & 270 & 43 & 35 & 10 & 116 & 18 \\
\hline At. 6 & 6 & 13.754 & 1.351 & 0.048 & 1.015 & 1.018 & 262 & 45 & 18 & 16 & 123 & 35 \\
\hline Mean & --- & 16.692 & 1.289 & 0.2068 & 1.012 & 1.017 & 268 & 46 & 32 & 18 & 127 & 23 \\
\hline
\end{tabular}

Legend as Table 1.

Table 3. Site-mean of the initial natural remnant magnetization (NRM) for the sites from Um Gir and Atshan-II uranium prospect areas, Central Eastern Desert, Egypt.

\begin{tabular}{|c|c|c|c|}
\hline Area & Site & $N$ & Int. $\left(\times 10^{-2} \mathrm{~A} / \mathrm{m}\right)$ \\
\hline \multirow{6}{*}{ Um Gir Area } & U G. 1 & 6 & 1.47 \\
\hline & U G. 2 & 5 & 1.32 \\
\hline & U G. 3 & 7 & 2.13 \\
\hline & U G. 4 & 6 & 2.13 \\
\hline & U G. 5 & 8 & 2.05 \\
\hline & U G. 6 & 5 & 1.52 \\
\hline \multirow{6}{*}{ El Atshan-II Area } & At. 1 & 5 & 1.40 \\
\hline & At. 2 & 7 & 1.5 \\
\hline & At. 3 & 7 & 3.7 \\
\hline & At. 4 & 6 & 2.6 \\
\hline & At. 5 & 7 & 0.81 \\
\hline & At. 6 & 6 & 1.84 \\
\hline
\end{tabular}

$N:$ Number of samples in each site; Int: Intensity of magnetization. 


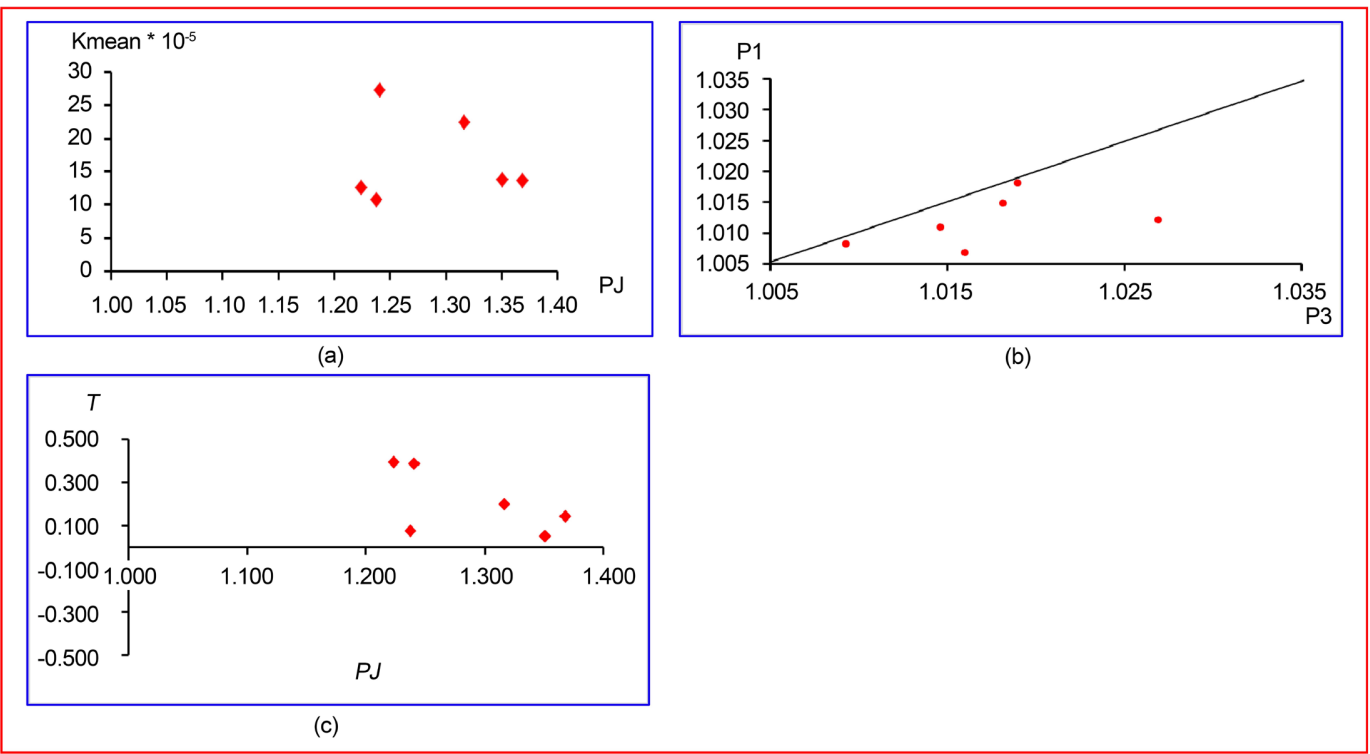

Figure 6. Relationships between: (a) Anisotropy degree $\left(P_{J}\right)$ and magnetic susceptibility $(K)$, (b) Foliation $\left(P_{3}\right)$ versus lineation $\left(P_{1}\right)$ and $(\mathrm{c})$ anisotropy degree $\left(P_{J}\right)$ and ellipsoid shape $(T)$ of the Bostonite rocks, El Atshan-II uranium prospect area, Central Eastern Desert, Egypt.

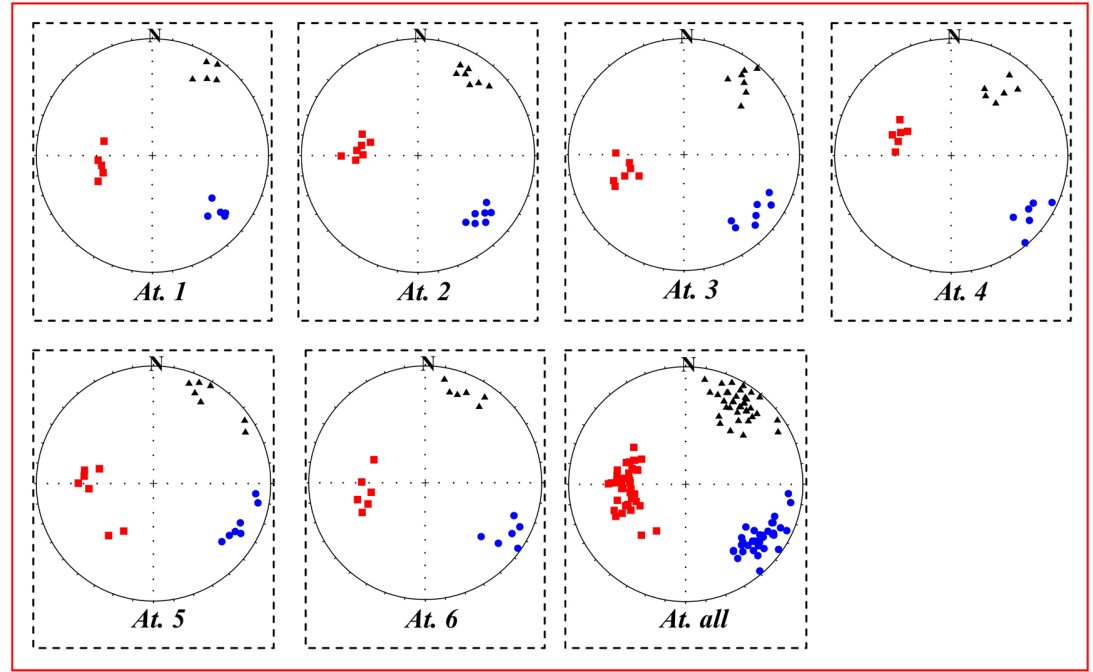

Figure 7. Equal-area lower hemisphere stereographic projections of the principal magnetic susceptibility axes for the 6 sites from the Bostonite of El Atshan-II uranium prospect area, Central Eastern Desert, Egypt. - Maximum axes $\left(K_{1}\right)$. $\boldsymbol{\Delta}$ Intermediate axes $\left(K_{2}\right)$. $\bullet$ Minimum axes $\left(K_{3}\right)$.

The AMS technique can be used in order to distinguish sills and dykes, a task that is almost impossible by using only field observations [22]. Previous geological work in this study proved that bostonite of Um-Gir exists as a dyke while bostonite of El Atshan-II occurs as a sill [6] [7]. These results agree well with the results of AMS of this study, where $\left(P_{1}>P_{3}\right)$. In addition the negative values of $T$ of Um-Gir bostonite reflect clearly magnetic lineation (prolate ellipsoid). Moreover, in El Atshan-II, where $\left(P_{3}>P_{1}\right)$, and the values of $T$ are positive, which indicate the predominance of magnetic foliation (oblate ellipsoid) over lineation. 


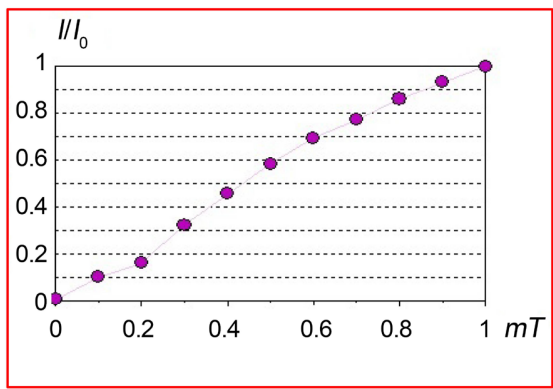

(a)

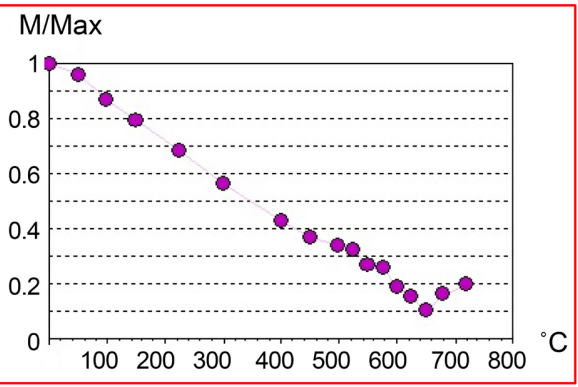

(b)

Figure 8. (a) \& (b). Isothermal remanent magnetization acquisition (IRM) behavior and subsequent thermal demagnetization of IRM for a representative sample from Um Gir uranium prospect area, Central Eastern Desert, Egypt.

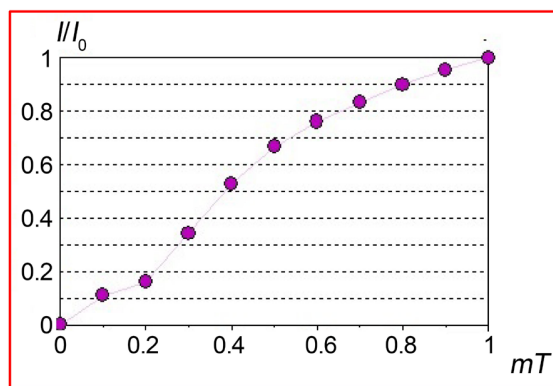

(a)

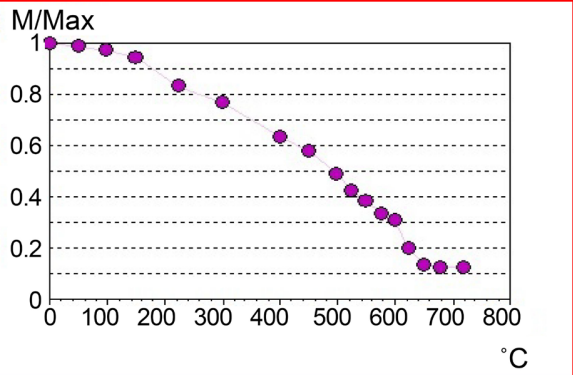

(b)

Figure 9. (a) \& (b). Isothermal remanent magnetization acquisition (IRM) behavior and subsequent thermal demagnetization of IRM for a representative sample from Atshan-II uranium prospect area, Central Eastern Desert, Egypt.

The relation between the susceptibility ellipsoid $T$, and the anisotropy degree, $P_{J}$, of all samples of bostonite of the two uranium prospect areas are located in a very close range and high degree of deformation, which indicate that these rocks fell under the influence of the same factors that led to their acquisition of secondary magnetic tissue, with high degree of deformation.

AMS measurements are able to identify the prevailing structures that affected bostonite rocks during or after their original emplacement. The determined AMS directions for the bostonite rocks in the two uranium prospect areas revealed relatively well-defined poles of magnetic foliation $\left(K_{3}\right)$, which were used to infer the flow directions. On the other hand, the foliation planes for Um-Gir bostonite dyke was low to moderate, with a nearly N-S direction. Meanwhile, the foliation planes of El Atshan-II sill were also, low to moderate and have a NNE direction. This result is in agreement with the results of ground magnetic survey [23].

One of the most interesting aspects of the application of magnetic fabrics is to get a new understanding of the mechanisms leading to fabric development in magmatic rocks. In the plutonic rocks where emplacement occurred through magma flow, the magnetic anisotropy is generally characterized by low values, less than 10 percent [24]. Thus, it is important to know if the observed fabrics were acquired during magmatic flow throughout pluton emplacement in the 
subsolidus stage or during a late tectonic stage after emplacement and cooling.

From this study, it was found that, the deformation magnitude ( $P_{J}$ parameter) was high with arithmetic means of 1.261 and 1.289 for the bostonites of Um-Gir and El Atshan-II respectively (Table 1 \& Table 2). This result indicates a high deformation reaching $26 \%$ and $29 \%$ for the bostonites of Um-Gir and El Atshan-II, respectively and suggests a secondary magnetic fabric.

\section{Conclusion}

The bostonite rocks of Um-Gir and El Atshan-II uranium prospect areas represent an important structurally-controlled radioactive anomaly. AMS results considered the bostonite rocks as non-magnetic rocks, reflecting the presence of hematite as the main ferromagnetic mineral. These results were in agreement with the measurements of (NRM) as well as the results of (IRM) for the two studied areas. Moreover, depending on the anisotropy degree $\left(P_{J}\right)$ values, the magnetic fabric of bostonites of the two areas is considered as secondary fabric. Using the AMS method, it was possible to know the shape of the rocks under surface, and whatever their shapes, dyke or sill. Thus, it was evident from two relations of both magnetic lineation $\left(P_{1}\right)$ and magnetic foliation $\left(P_{3}\right)$ with ellipsoid shape $(T)$ that, the bostonite rocks of Um-Gir clearly have magnetic lineation (prolate ellipsoid) as $\left(P_{1}>P_{3}\right)$ as well as the negative values of $T$. Meanwhile, for the bostonites of El Atshan-II, they have predominance of magnetic foliation as $\left(P_{3}>P_{1}\right)$, as well as the positive values of $T$. Moreover, through AMS results, the whole structures that affected the bostonite rocks of the two studied areas were clear, where the foliation planes for Um-Gir bostonite dyke show low to moderate inclination, with a nearly N-S direction, while the foliation planes of El Atshan-II sill indicated also, low to moderate inclination and has a nearly NNE SSW direction.

\section{Acknowledgements}

The author is deeply grateful to Prof. Dr. Mohammed H. M. Youssef, and Prof. Dr. Assran S. M. Assran, Exploration Division, Nuclear Materials Authority, Egypt, for their critical re-view of the manuscript.

\section{Conflicts of Interest}

The author declares no conflicts of interest regarding the publication of this paper.

\section{References}

[1] Sagnotti, L., Macrì, P., Lucchi, R., Rebesco, M. and Camerlenghi, A. (2011) A Holocene Paleosecular Variation Record from the Northwestern Barents Sea Continental Margin. Geochemistry, Geophysics, Geosystems, 12, Article No, Q11Z33. https://doi.org/10.1029/2011GC003810

[2] Hrouda, F., Ježek, J. and Chadima, M. (2020) Anisotropy of Out-of-Phase Magnetic Susceptibility as a Potential Tool for Distinguishing Geologically and Physically Con- 
trolled Inverse Magnetic Fabrics in Volcanic Dykes. Physics of the Earth and Planetary Interiors, 307, Article ID: 106551. https://doi.org/10.1016/j.pepi.2020.106551

[3] Mahdy, M.A., Salmaan, A.B. and Assaaf, H.S. (1994) Bostonite Rocks as Additional Uranium Resources in Egypt. 2nd International Conference on the Geology of the Arab World, Cairo University, 77-96.

[4] Rochette, P., Jackson, M. and Aubourg, C. (1992) Rock Magnetism and the Interpretation of Anisotropy of Magnetic Susceptibility. Reviews of Geophysics, 30, 209226. https://doi.org/10.1029/92RG00733

[5] Assaf, H.S. (1966) Ground Exploration and Geological Studies on Some Radioactive Occurrences in the Area South of Kosseir. M.Sc. Thesis, Faculty of Science, Ain Shams University, Cairo, $325 \mathrm{p}$.

[6] El-Kassass, I.A. (1969) Comparative Geological Investigation of the Radioactive Mineralizations in the Central Eastern Desert, Egypt (U.A.R). M.Sc. Thesis, Faculty of Science, Ein-Shams University, Cairo, 358 p.

[7] Hussein, H.A. and El-Kassass, I.A. (1980) Some Favorable Host Rocks for Uranium and Thorium Mineralization in Central Eastern Desert Egypt. Annals of the Geological Survey of Egypt, 10, 897-908.

[8] El-Amin, H. (1971) Structural Controls of the Radioactive Mineralization in the Central Eastern Desert Egypt. M. Sc. Thesis, Faculty of Science, Cairo University, Geza, $100 \mathrm{p}$.

[9] Clark, D.A., French, D.H., Lackie, M.A. and Schmidt, P.W. (1992) Magnetic Petrology: Application of Integrated Rock Magnetic and Petrological Techniques to Geological Interpretation of Magnetic Surveys. Exploration Geophysics, 23, 65-68. https://doi.org/10.1071/EG992065

[10] Fuller, M.D. (1963) Magnetic Anisotropy and Paleomagnetism. Journal of Geophysical Research (1896-1977), 68, 293-309.

https://doi.org/10.1029/JZ068i001p00293

[11] Stephenson, A., Sadikun, S. and Potter, D.K. (1986) A Theoretical and Experimental Comparison of the Anisotropies of Magnetic Susceptibility and Remanence in Rocks and Minerals. Geophysical Journal International, 84, 185-200. https://doi.org/10.1111/j.1365-246X.1986.tb04351.x

[12] Clark, D.A., Emerson, D.W. and Kerr, T.L. (1988) The Use of Electrical Conductivity and Magnetic Susceptibility Tensors in Rock Fabric Studies. Exploration Geophysics, 19, 244-248. https://doi.org/10.1071/EG988244

[13] Tarling, D.H. (1971) Principles and Applications of Palaeomagnetism. Chapman \& Hall, London, $164 \mathrm{p}$.

[14] Molspin Ltd. (1998) Minisep (Magnetic Susceptibility and AMS Meter). User Manual, Molspin Ltd., UK.

[15] Nagata, T. (1961) Rock Magnetism. 2nd Edition, Maruzen, Tokyo, 550 p.

[16] Jelinek, V. (1981) Characterization of the Magnetic Fabric of Rocks. Tectonophysics, 79, T63-T67. https://doi.org/10.1016/0040-1951(81)90110-4

[17] Blasely, J.R. and Buddington, A.F. (1960) Magnetic Susceptibility Anisotropy and Fabric of Some Adirondack Granites and Orthogneisses. American Journal of Science, 258A, 6-20.

[18] Stacey, F.D., Joplin, G. and Lindsay, J. (1960) Magnetic Anisotropy and Fabric of Some Foliated Rocks from S. E. Australia. Geofisica pura e applicata, 47, 30-40. https://doi.org/10.1007/BF01992481

[19] Flinn, D. (1962) On Folding during Three-Dimensional Progressive Deformations. 
Quarterly Journal of the Geological Society, 118, 385-428. https://doi.org/10.1144/gsigs.118.1.0385

[20] He, J., Chen, B. and Wang, Y. (2021) Structural Deformation in Kaladawan of North Altun Orogenic Belt, NW China: Constraints from Magnetic and EBSD Fabrics. Geological Journal, 56, 3081-3096. https://doi.org/10.1002/gj.4090

[21] Ellwood, B.B. and Wenner, D.B. (1981) Correlation of Magnetic Susceptibility with ${ }^{18} \mathrm{O} /{ }^{16} \mathrm{O}$ Data in Late Orogenic Granites of South Appalachian Piedmont. Earth and Planetary Science Letters, 54, 200-202. https://doi.org/10.1016/0012-821X(81)90003-0

[22] Zananiri, I. and Kondopoulou, D. (2004) Anisotropy of Magnetic Susceptibility (AMS) in Volcanic Formations: Theory and Preliminary Results from Recent Volcanics of Broader Aegean. Bulletin of the Geological Society of Greece, 36, 13081315. https://doi.org/10.12681/bgsg.16474

[23] El-Salam, H.F.A. (2014) Geophysical Studies for UmGir-El Atshan-II uranium Prospect Area, Central Eastern Desert, Egypt. M.Sc. Thesis, Faculty of Science, Mansoura University, Cairo, $126 \mathrm{p}$.

[24] Hargraves, R.B., Johnson, D. and Chan, L.Y. (1991) Distribution Anisotropy: The Cause of AMS in Igneous Rocks. Geophysical Research Letters, 18, 2193-2196.

https://doi.org/10.1029/91GL01777 